\title{
MEKANIK VENTILATÖRLERIN TARIHSEL SÜREÇ IÇiNDEKI GELIŞiMi
}

\section{THE HISTORICAL DEVELOPMENT OF MECHANICAL VENTILATORS}

\author{
Tevfik Kaplan, Serdar Han \\ Ufuk Üniversitesi Tıp Fakültesi, Göğüs Cerrahisi Anabilim Dalı, Ankara, Türkiye \\ e-mail: tevfikkaplan@yahoo.com \\ DOI:10.5152/tcb.2014.024
}

\section{Özet}

Solunumun amacı ister spontan olsun ister yapay olsun homeostazı sağlamaktır. Mekanik ventilatörler soluma işlemini tarafımızdan ayarlanan paremetrelere göre otomatik yapan elektronik, mekanik veya pnömatik kontrollü aygitlardır. Tarihsel süreç içerisinde anestezideki ve yoğun bakımdaki gelişmeler bu cihazların da çalıştırıcı mekanizmaya göre, negatif veya pozitif basınç kullanımına göre, soluk völümünün meydana gelişine göre veya ventilasyon peryoduna göre değişik şekillerde sınıflandırılmasına neden olmuştur. Fakat modern ventilatörler birçok sınıflamayı bir arada bulunduran kompleks cihazlar halini almıştır. Yakın bir gelecekte ise bu cihazların akıllı cihazlara dönüşerek tüm ayarlamaları hastanın durumuna göre otomatik ayarlayarak uygulaması mümkün olacaktır.

Anahtar kelimeler: Ventilatörler, Tarihçe, Ventilasyon Modları

\section{GiRiş}

Ventilasyonun gelişimi tarihsel olarak Hipokratın havayı bilimsel olarak değerlendirmesi ve suda boğulma vakalarında nefes borusu vasıtasıyla hastaya hava gönderilmesi gerekliliğini bildirmesiyle başlar. Yayınlanmış ilk raporlarda yapay solunum sağlam bir kişinin hastaya ağızdan ağıza solunum yaptırması olarak bildirilmiştir. On sekizinci yüzyılda boğulma durumlarında ağızdan ağıza yapılan suni solunum birinci basamak tedavi haline gelmişti. Makineler tarafından otomatik olarak yapılan suni solunumun ilkel şekli ise ancak 150 yıl sonra ortaya çıkabilmişti. Draeger tarafından 1907 yılında ilk olarak bu makineler ticari olarak üretilmeye başlandı. Ancak sadece yeniden canlandırma veya kurtarma aparatları olarak kullanılmaktaydılar $(1,2)$.

Çelik ciğer olarak da bilinen negatif basınçla çalışan klasik tank ventilatörü 1930'lu yıllarda Amerika'daki

\begin{abstract}
The purpose of respiration, whether artificial or spontaneous, is to get homeostasis. Mechanical ventilators are electronic, mechanical, or pneumatic devices that are doing respiration automatically according to the process of the parameters that are set by us. In the historical process, the developments in anesthesia and intensive care units have led us to classify these devices according to the actuating mechanism, the use of negative and positive pressure, occurrence of respiratory volume, or according to the ventilation period. However, many modern ventilators are complex devices with a combination of these classifications. In the near future, these devices will turn into smart devices, and all adjustments will be done automatically according to the patient's conditions.
\end{abstract}

Key words: Ventilators, History, Ventilation Modes

polio salgınında kullanımıştır. Ancak bu cihazların çok yer kaplaması, hasta bakımının iyi olmaması, dolaşımı etkilemesi gibi yan etkileri mevcuttu (3).

Cerrahların toraksın içine girme cesaretine kadar yapay solunum cihazlarının anestezi işlemlerinin içine girmesi yavaş olmuştur. Spontan solunumu olan hastada yapılan göğüs cerrahisi operasyonlarında plevral aralığın açılmasıyla pnömotoraks, mediastinal shift ve yüksek mortalite kaçınılmaz olup, pozitif basınçlı ventilasyonun kullanılmasıyla bu istenmeyen durumların hepsi ortadan kalkmıştır (2).

Otomatik yapay ventilatörlerin gelişmesindeki diğer bir adım ise 1952 yılında Danimarka'daki polio salgınıdır. Danimarkalı doktorlar polioya bağlı mortaliteyi, trakeostomi ve manuel pozitif basınçlı ventilasyon ile \%80'de \%20'ye düşürmeyi başarmışlardır. Hastaların elle ventilasyonunun sağlanmasında 1400 üniversite öğrencisi çalışmıştır $(2,4)$. 
Pozitif basınçlı ventilatörler ile endotrakeal tüp yoluyla yapılan pozitif basınçlı ventilasyon 1960-1970'li yıllarda negatif basınçlı ventilasyonun yerini aldı. Daha sonraki yıllarda teknolojideki ve özellikle elektronikteki gelişmeler ile bugünün modern ventilatörlerini ortaya çıkardı.

\section{MEKANIK VENTILATÖRLERIN SINIFLAMASI}

Mekanik ventilatörler, toraksın etrafındaki basıncını azaltan negatif basınçlı ventilatörler ile solunum yolları içindeki basıncı arttıtan pozitif ventilatör olarak ikiye ayrılmaktadır.

1. Negatif basınçı ventilatörler sadece göğüs bölgesini veya boyundan itibaren tüm vücudu saran sert bir tank şeklindedir ve demir akciğer olarak adlandırılmaktadır (Resim 1). Bu tankın içindeki basınç intermittan azaltılıp respiratuar kasların fonksiyonlarını taklit ederek akciğerin genişlemesine olanak sağlamaktadır. $\mathrm{Bu}$ ventilatörler eskiden polio salgınları zamanında kullanılmış olup günümüzde ise uzun süreli solunum desteği ihtiyacı olan veya kas güçsüzlüğü olan hastalarda kullanılmaktadır. Çoğu tank ventilatörler kontrollü ventilasyon sağlar ve hastanın spontan solunum eforuna izin vermez. Tidal volümün sağlanması akciğerin rezistans ve kompliyans kapasitesine bağlıdır. Tank ventilatörler nörolojik nedenlerden dolayı ventilasyonu tam yapamayan, normal akciğere sahip hastalarda gaz alışverişini sürdürmek için iyi bir seçenek olabilir. $\mathrm{Bu}$ ventilatörlerde entübasyona veya nemlendirmeye gerek yoktur. Hasta konuşabilir, yemek yiyebilir. En önemli dezavantajları büyük ve hantal oluşlarıdır $(3,5)$.

2. Pozitif basınçlı ventilatörler ile hava yoluna atmosfer basıncının üzerinde pozitif basınç verilerek alveol ile hava yolu arasında basınç gradienti oluşturulur. Ventilatörler inspirasyonu kontrol eden makinelerdir, ekspirasyon ise pasif bir işlemdir. Bundan dolayı sınıflandırma inspirasyon sırasındaki gazın veriliş şekline göre olmaktadır. Ventilatörler inspirasyonu, basınç veya hacim kontrollü soluklar şeklinde hastaya uygulayabilir. İnspirasyondan ekspirasyona geçiş mekanizmalarına göre zaman, basınç, akım veya hacim devirli olarak sınıflandırilırlar (Resim 2) $(2,4)$.

\section{1. Volüm Ayarlı Ventilatörler}

Bu tür cihazlar genellikle akım jenaratörleriyle çalışırlar. Bu cihazların avantajı, sabit veya değişken akım modelleri ile akciğerdeki değişikliklerden bağımsız olarak, sabit tidal volüm oluşturabilmesidir. Genellikle volüm ya da zaman siklusludur. Modern ventilatör-

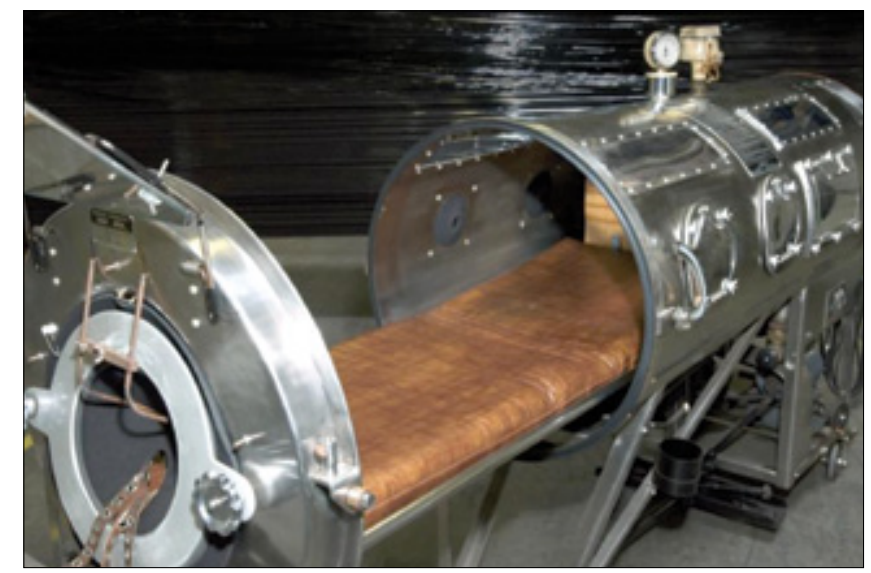

Resim 1. Demir Akciğer (Resim, Center for Disease Control and Prevention's Public Health Image Library'den alınmıştır.)

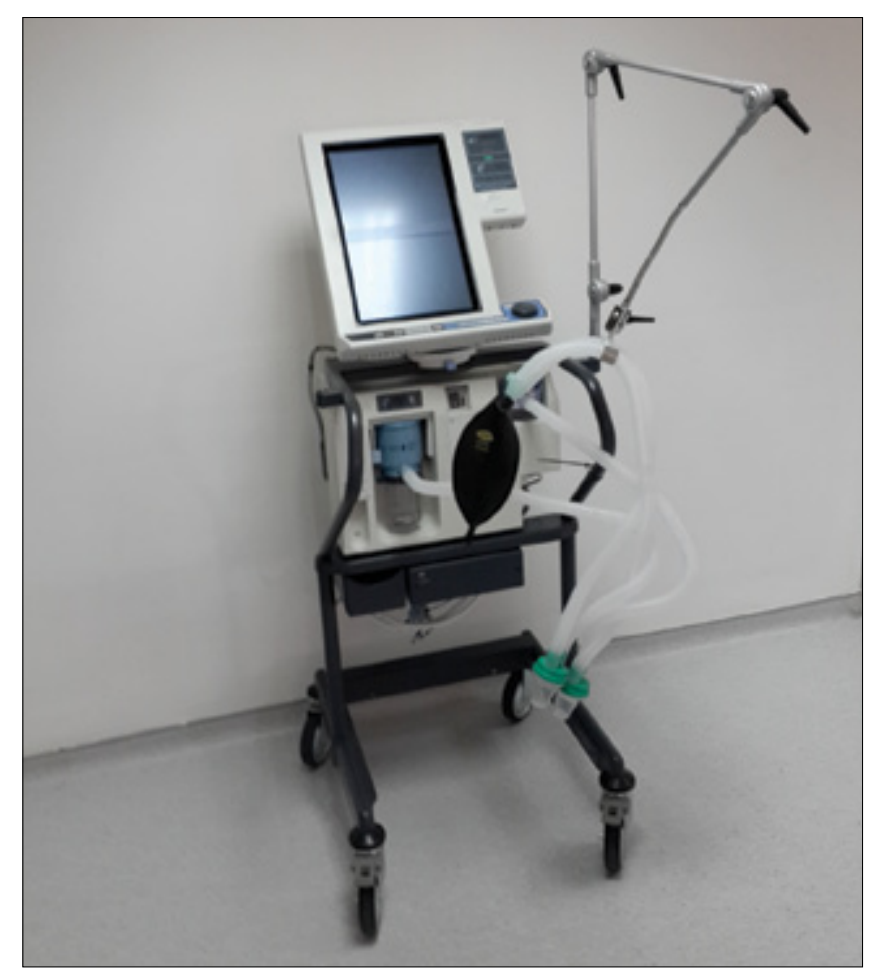

Resim 2. Modern bir ventilatör cihazı (Ufuk Üniversitesi Tıp Fakültesi Arşivinden)

lerde hava yolu basıncının çok artması durumunda inspirasyonda gaz akımının kesilmesini ve geriye kalan verilmemiş tidal volümün atmosfere çıkmasını böylece hava yolu basıncının tehlikeli düzeye çıkmasını önleyen emniyet sistemleri mevcuttur. Akut solunum yetmezliğinde belirlenen dakika hacminin hastaya verilmesini garanti etmesi nedeniyle volüm ayarlı ventilasyonun uzun süre en uygun seçenek olduğuna inanılmıştı. Günümüzde ise volüm ayarlı ventilasyonun, akciğerin mekanik özellikleri değiştiğinde yüksek inflasyon basınçları oluşturarak barotravmaya yol açtığı 
ve hastanın ihtiyacına göre solunumu sağlayamadığı kabul edilmektedir.

\subsection{Basınç Ayarlı Ventilatörler}

Basınç ayarlı ventilasyonda önceden ayarlanmış olan basınç, oluşturulana kadar ventilatör hastanın havayoluna pozitif basınç uygular ve inspirasyonu sağlar. Basınç kullanılan moda bağlı olarak zorunlu veya spontan solukla uygulanabilir. Bu tip ventilasyonda tidal volüm ve inspiratuar akım profili respiratuar sistemin direnci ve hastanın inspiratuar gücüne göre değişir.

\section{VENTILASYON MODLARI}

Ventilasyon modu ventilatörlerin nasıl davrandığını tarif etmek için kullanılan bir terimdir. Tarihsel süreç içerisinde inspirasyonun başlamasını sağlayan yöntemler mod olarak tanımlanmışlardır. Ventlasyon modları genel olarak toraks içinde oluşan basınç şekline, hasta ventilatör bağlantısına, inspirasyon akımının başlama şekline, ispirasyon akımının hedefine, inspirasyondan ekspirasyona geçiş şekline göre farklılaşır.

1. Yardımlı Modlar: Hastanın solunumunun olduğu ancak yetersiz olduğu durumlarda solunum ventilatör tarafından desteklendiği modlardır.

2. Kontrollü Modlar: Soluması olmayan ya da değişik nedenlerele nöromusküler ilaçlar verilerek solunumu durdurulan hastalarda, ventilasyonun tamamen ventilatör tarafından yapılan ve hastanın hiç eforunun olmadığı modlardır.

Eskiden genellikle kontrole modlar kullanılır ve hastalar ventilatörden ayrılacağı dönemde yardımlı modlara geçilirdi. Günümüzdeki yaklaşım ise hastanın uyanık veya sedasyon ile yardımlı modlar ile ventile edilmesi, mutlak gerektiği zaman kontrole modlara geçilmesidir. Yardımlı modlar kullanılarak hasta ve ventilatör senkron çalışabilmekte, sedasyon intiyacı azalabilmekte, solunum kaslarının atrofisi önlenebilmekte ve hasta ventilatörden daha kolay ayrılabilmektedir.

3. Yüksek Frekanslı Ventilasyon: Bu tip ventilasyonda, düşük tidal volümlerle yüksek frekansta ventilasyon yapılır. Üç çeşidi mevcuttur. 1) Yüksek frekanslı pozitif basınçı ventilasyon, 2) Yüksek frekanslı jet ventilasyon, 3) Yüksek frekanslı ossilatuar ventilasyon Klinik olarak yüksek frekanslı ventilasyon yetişkin yoğun bakım ünitelerinde ve endoskopi, otorinolaringoloji, toraks, karın ve beyin cerrahisi ameliyatlarında, çeşitli hastalarda kullanılmaktadır. En önemli özelliği hem acil hem de elektif ventilasyon için trakeal veya transtrakeal yolla krikotiroid membranda dahil yerleştirilen çok ince bir kanül ile yeterli ventilasyonun sağlanabilmesidir.

\section{YARDIMLI MODLAR}

1.1. Asiste Solunum (Asisted Ventilation-AV): Hastanın solunum eforu ile tetiklenen ve makinenin tidal volümü belirlediği moddur. Desteksiz spontan sonluma izin vermez. Şuuru açık ve kısa süreli ventilasyon gereken hastalar için uygundur. Apne durumunda ventilasyon sağlanamaz.

1.2. Asiste Kontrollü Ventilasyon (AsistedControl-Ventilation-ACV): Hastanın eforu ile tetiklenen ve tidal volümün ventilatör tarafından belirlendiği moddur. Asiste solunumdan farkı apne durumunda ventilatör önceden belirlenen frekans ve tidal volümde kontrollü solunuma geçer. Spontan desteksiz solumaya izin vermez. İki şekilde uygulanır, a) Volum hedefli asiste kontrollü ventilasyon, b) Basınç hedefli asiste kontrollü ventilasyon.

1.3. Aralıklı Zorunlu Ventilasyon (Intermittent Mandatory Ventilation-IMV-Senkronize Intermittent Mandatory Ventilation-SIMV): Spontan ve kontrollü solunum kombinasyonudur. Önceden belirlenen zorunlu solumalar yaptırılırken arada ventilatör desteği olmayan spontan solumaya izin veren bir modtur. Senkronize olan modunda (SIMV) zorunlu solumaların duyarlılık ayarı ile hasta tarafından tetiklenmesi böylece hasta ile ventilatörün senkronize çalışması sağlanmış olur.

1.4. Basınç Destekli Ventilasyon (Pressure Support Ventilation-PSV): Her bir solunumun hasta tarafından desteklendiği basınç destekli akım kontrollü bir ventilasyon modudur. Bu ventilasyonun amacı artmış inspiratuar rezistansı yenmektir. Apne durumunda ventilasyon sağlanamaz.

1.5. Devamlı Pozitif Havayolu Basıncı (Continous Positive Airway Pressure-CPAP): Hasta spontan solunumdadır ve ventilatör hem inspirasyonada hem de ekspirasyonda hava yoluna pozitif basınçlı hava verir. Amaç akciğer volumlerini ve oksijenasyonu arttırmak, alveolleri açık tutup atelektazileri açmak ve önlemektir.

1.6. Ekspirasyon Sonu Pozitif Basınç (Positive End Expiratory Pressure-PEEP): Pozitif basınçlı ventilasyonlarda, ekspirasyonda belirli bir basıncın altına inilmesine izin verilmemesidir. Amacı ortalama hava yolu basıncını artırmak, atelektazileri önlemek, akci- 
ğerleri açmak ve fonksiyonel rezidüel kapasiteyi arttırıp oksijenasyonu arttırmaktır.

\section{KONTROLLÜ MODLAR}

Hastanın solunumundan bağımsız olarak mekanik ventilasyon yapılmasıdır. Bu modun zaman döngüsü olup, hasta spontan olarak soluk alıp veremez. Bu açıdan, spontan solunum olmayan hastalarda ya da spontan sonlumu bloke edilen hastalarda kullanılır. Volüm kontrollü, basınç kontrollü veya ters oranlı ventilasyon modunda kullanılabilir (5-7).

Sonuç olarak mekanik ventilatörler son 50 yıl içerisinde basit mekanik aletlerden mikroişlemcisi olan ve her türlü ventilasyon modunda solunumu sağlayan karmaşık cihazlar haline gelmiştir. Yakın bir gelecekte ise bu cihazların akıllı cihazlara dönüşerek tüm ayarlamaları hastanın durumuna göre otomatik olarak kendisinin ayarlayıp uyguladığı cihazlara dönüşeceği aşikârdır.

\section{KAYNAKLAR}

1. Bilgin TE. Anestezide Öncüler ve Keşifler Tarihi. Lokman Hekim Journal 2013;3:37-52.

2. Young JD, Sykes MK. A Assisted ventilation. 1. Artificial ventilation: history, equipment and techniques. Thorax 1990;45:753-8. [CrossRef]

3. Kacmarek RM. The mechanical ventilator: past, present, and future. 2011;56:1170-80.

4. Öz H, Köksal GM. Mekanik Ventilasyon. Solunum 2006;8:37-46.

5. Chatburn RL, Volsko TA. Mechenical Ventilators. In:Wilkins RL, Stoller JK, Scanlan CL, eds. Egan's Fundementals of Respiratory Care. 8th Edition. Mosby 2003:929-62.

6. Esteban A, Anzueto A, Alia I, Gordo F, Apezteguia C, Palizas $F$ et al. How is mechanical ventilation employed in the intensive care unit? An international utilization review. Am J Respir Crit Care Med 2000;161:1450-8. [CrossRef]

7. Carroll GC, Tuman KJ, Braverman B, Logas WG, Wool N, Goldin M, et al. Minimal positive end-expiratory pressure (PEEP) may be "best PEEP". Chest 1988;93:1020-5. [CrossRef] 